\title{
Como combater a Tillandsia Usneoides
}

\author{
Philipe W. C. de Vasconcellos \\ Heitor W. S. Montenegre \\ da Seção Técnica de Horticultura da
}

Escola Superior de Agricultur.

"Luiz de Queirox" da

Universidade de Säo Paulo 
Insistentes pedidos feitos por fazendeiros de Capivari e outras regioes do estado, levaram-nos a estudar um combate effcaz e sobretudo economico a Tillandsia usneoides, mais conkecida vulgarmente por "barba de velho". (Flgs. 1 e 2).

Ista planta é da familia Bromeliaceae, epifita, isto 6, ela nó parsisita a planta hospedeira, tendo apenas açio puramente nieçanica de agarrar-se, por intermédio de suas ralzes, à mestna.

Muitos botánicos săo de opintăo que ela năo prejudica a plantr aive a hospeda. Somos, porém, de parecer, que a T. usneoides, prejudica demasiadamente as plantas hospedeiras cheganas a causar-lhes a morte quando em grande numero. Chegámos a esta conclusáo quando observamos que suas raires, penetrando profundamente na casca, formam um verdadeiro anel em torno das ramos, dificultando a circulaçáo da seiva.

Sem combate, esta plantinha se propaga com vertiginosa rapiciez, principalmente nas árvores de casca um tanto aspera, onde is sementes da $T$. usneoldes, levadas pelo vento, se alojam e al gerininam.

ìté entán, o método aconselhado era o da retirada manual daqiela bromelíacea, processo este, muito fácil de se aconselhar, porém, pouco viável na prática, especialmente nas grandes árvcres.

Im agosto de 1946 resolvemos aplicar uma calda mista cuja compasiçáo era a seguinte:

Emulsáo de óleo Diesel e sabro ............ 2 qullos 2o bordalez $\ldots \ldots \ldots \ldots \ldots \ldots \ldots \ldots \ldots \ldots \ldots$ 1 quilo

Arseniatc de cálcio $\ldots \ldots \ldots \ldots \ldots \ldots \ldots \ldots \ldots .250$ grs.

Nisctina $\ldots \ldots \ldots \ldots \ldots \ldots \ldots \ldots \ldots \ldots$ de 20 grs. de tumo Aglie. .............................. 100 lltros

Ista experiencia fol realizada em dois Ipes do parque da Escoia Superior de Agricultura "Lulz de Queiroz" (Fig. 3) que ness2 epcca se apresentavam completamente despidos de thas. 


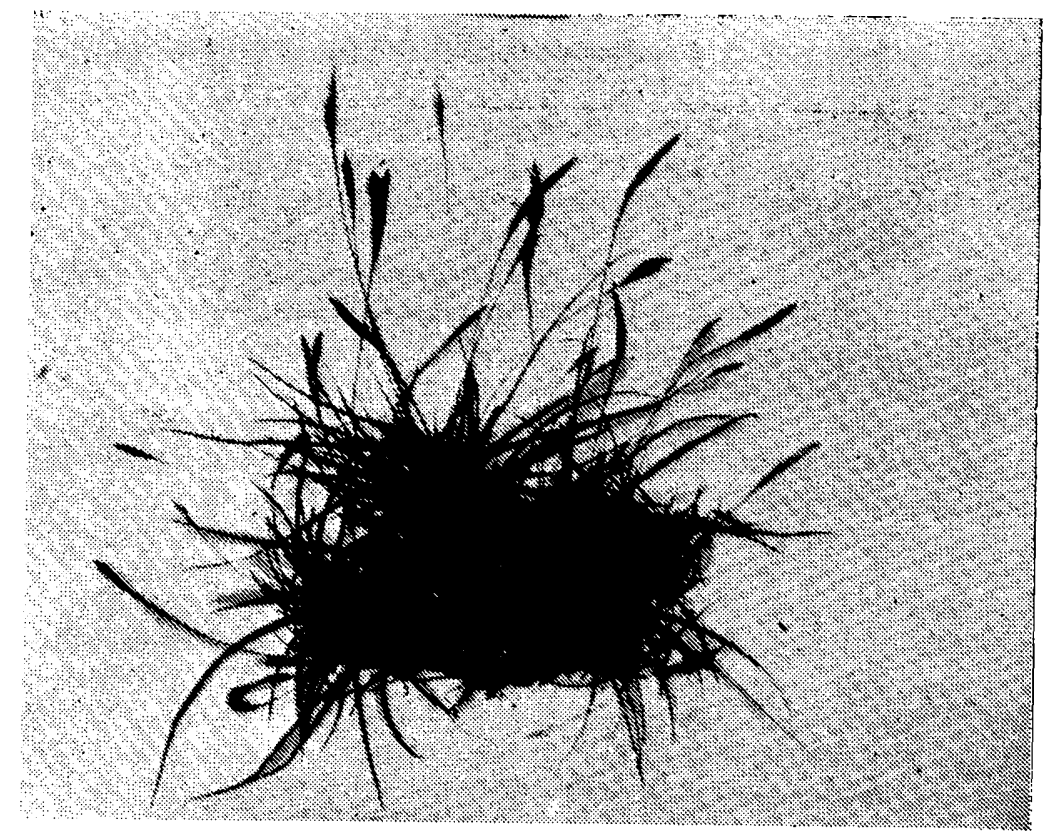

Fig. 1 - T. usneoides c/ flores

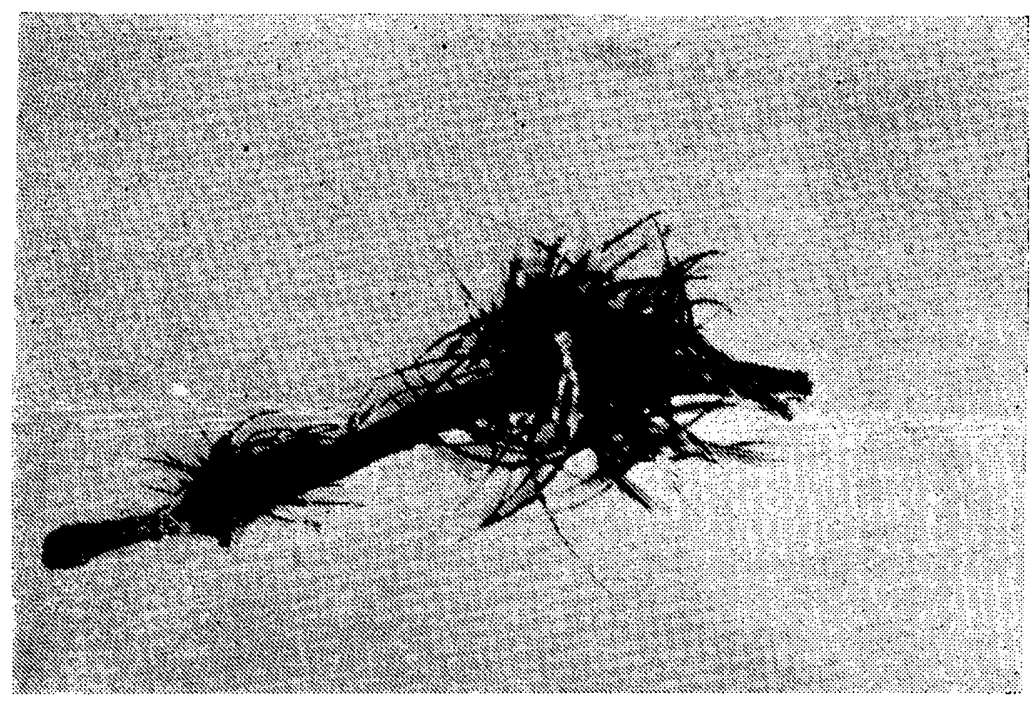

Fig. 2 - Ramo infestado de Tillandsia 


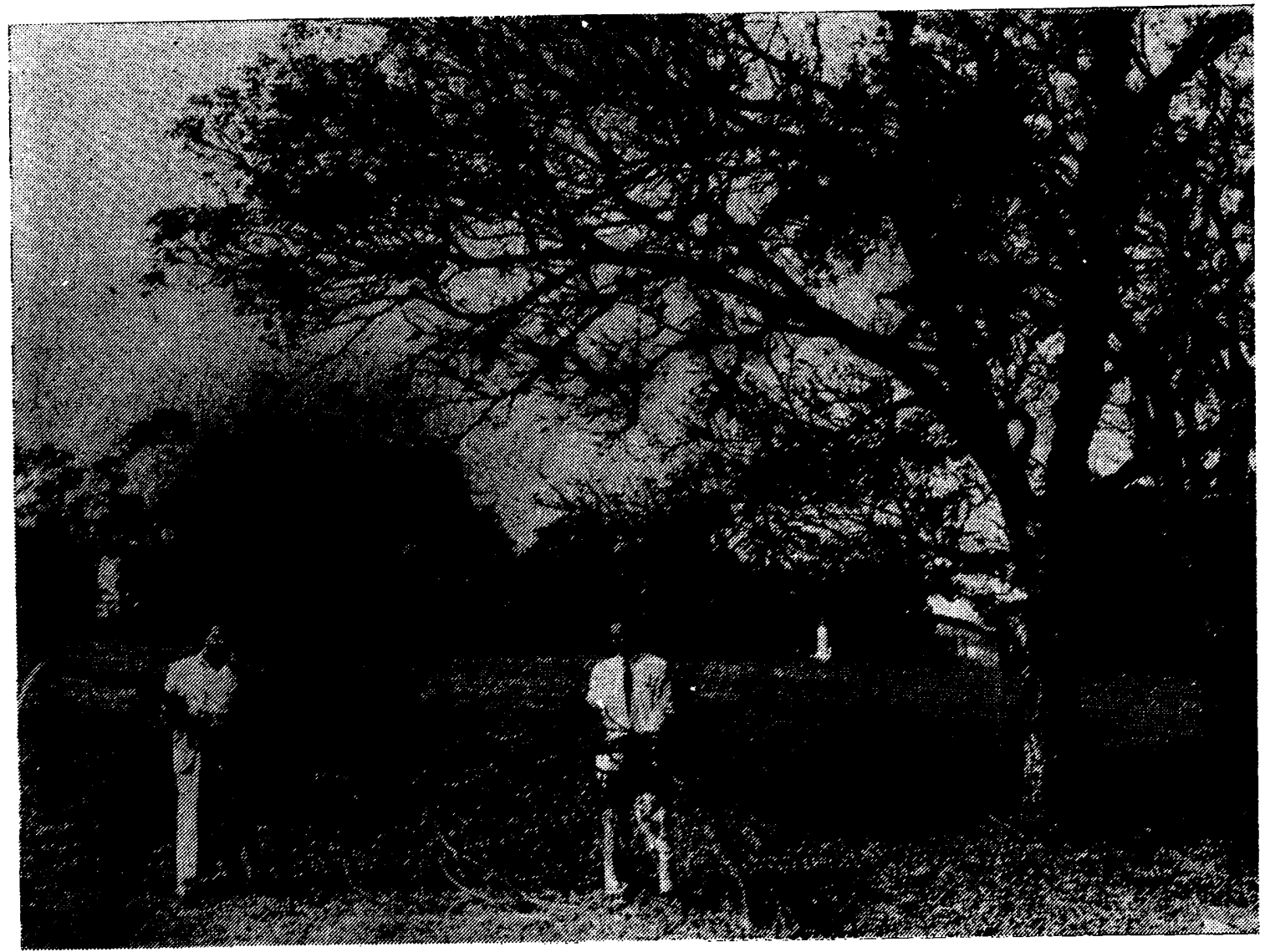

Fig. 3 - Dois ipês, do parque da Escola Superior de Agricultura "Luiz de Queiroz", totalmente infestados de T. usneoides 
Num perifodo de observaçăo de 2 meses, pudemós constatar que aquela praga sofreu superficialmente, isto 6 , apenas as partes n:ais tenras, com as extremidades de suas fllamentosas tolhas tinham sidi queimadas. Outro inconveniente era a propriedade que possui o po bordalez de ser preservativo da materta organice, no caso da Tillandsia, de suas raises preses as árvores. Dal Urános a conclusăo que a percentagem usada (2\% de emulsto) ainca era pequena, e ao mesmo tempo resolvemos simplificar a calca, aplicando apenas a emulsto, com a seguinte rórmula :

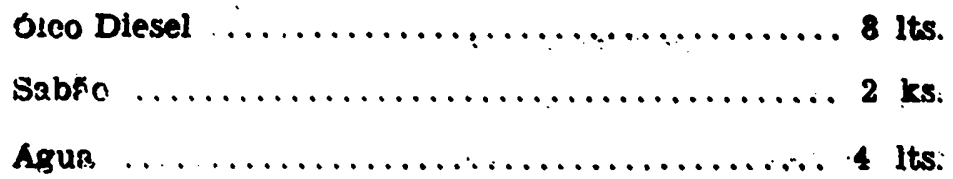

Modo de preparar a emulsão : -

Para que haja um bom emulsionamento é imprescindivel proceler da seguinte maneira : - colocam-se em uma vasilha as 8 litr. s de cleo levando-se em seguida ao fogo; ao mesmo tempo, am nutra vastlha, aquecem-sé os dols quillos dé stablo comum dirsolvidos em 4 litros dágua. Quando os dols estiverém bem aquecidos misturai-se o oleo ao sabro, despejando-o em flio fino e agitario' concomitantemente, e com força alte produtirse 0 emulsionamento do óleo. Pode-se tambem usar uma bomba aspirunte-premente, na trasfega da mistura quente, de um para outro reciplente, por duas ou tres vezes. Deixa-se, em seguide, esfriar A pasta resultante pode ser usada na concentragko desejada.

Vesta epoca (Out.) as plantas se achavam completamente cobe:tas som slia roupagem verde o que nos impossiblititatia de continuar com a experiencia, pois, a emulsto usada em percentagem mais elevada poderia ser prejudictal as plantas devido a stu alto teor, determinando talvez, o crestamento das Polkns: 
Resolvemos mudar o rumo de nossa experiência com o fito dê gainharmos tempo. Cortámos então 6 galhos de 1,m5 de comprimentr, bastante infestados de $\mathbf{T}$. usneoides e amarrámos cada um dêles a uma vara de bambú, prêsa a dois eucalíptos.

Como esta praga é epífita em nada alteraria que o ramo estivesse ou nâo com vida.

Os galhos receberam o seguinte tratamento: -
( 1.c galho - emulsão a $2 \%$
O $2 .^{\circ}$ galho - emulsão a $4 \%$
C 3.0 galho - emulsão a $6 \%$
O 4." galho - emulsão a $10 \%$
$05 .^{\circ}$ galho - emulsão a $15 \%$
O $6 .^{\circ}$ galho - testemunha.

esses tratamentos foram feitos, com um purverizador de cośtas marca Dobbins, (não se deve usar pulverizador com válvula de borr?cha pois a emulsão a estraga), no dia 30-10-46 e 3 meres fepois pudemos ver coroada de êxito nossa experiência cum o seguinte resultado da susceptibilidade da Tillandsia :

No 1. galho - c/ emulsão a $2 \%$ - náo houve alteraçá .

No $2 .^{\circ}$ gạlho - c/ emulsão a $4 \%$ - parte morreu, parte não

No $3 .^{\circ}$ gaiho - e. emulsáo a $6 \%$ - morreu completamente.

No $4 .^{\circ}$ galho - c/ emulsão a $10 \%$ - idem.

No $5 .^{\circ}$ galho - c/ emulsão a $15 \%$ - idem.

N. 6 - testemunha - não alterou - em otimo estado. 
Com estes resultados tirámos as seguintes conclusరes:

a) quie a partir de $6 \%$ a emulš̃o acima usada, combate eficazmante a praga $\mathbf{T}$. usneoides.

b) que também os liquens foram fortemente afetados a essa percentagem.

c) näo se conhecendo ainda a resistencia das folhas as diversas percenteigens de emulsão, convem fazer o tratamento. para as hibernantes; quando despidas. 